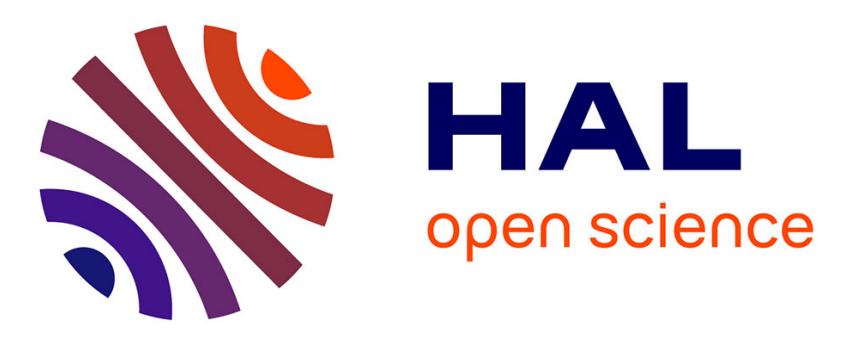

\title{
Modelling An Absorption System Assisted By Solar Energy
}

\author{
J.R. García Cascales, F. Vera García, J.M. Cano Izquierdo, J.P. Delgado \\ Marín, R. Martínez Sánchez
}

\section{To cite this version:}

J.R. García Cascales, F. Vera García, J.M. Cano Izquierdo, J.P. Delgado Marín, R. Martínez Sánchez. Modelling An Absorption System Assisted By Solar Energy. Applied Thermal Engineering, 2010, 31 (1), pp.112. 10.1016/j.applthermaleng.2010.08.025 . hal-00685785

\section{HAL Id: hal-00685785 https://hal.science/hal-00685785}

Submitted on 6 Apr 2012

HAL is a multi-disciplinary open access archive for the deposit and dissemination of scientific research documents, whether they are published or not. The documents may come from teaching and research institutions in France or abroad, or from public or private research centers.
L'archive ouverte pluridisciplinaire HAL, est destinée au dépôt et à la diffusion de documents scientifiques de niveau recherche, publiés ou non, émanant des établissements d'enseignement et de recherche français ou étrangers, des laboratoires publics ou privés. 


\section{Accepted Manuscript}

Title: Modelling An Absorption System Assisted By Solar Energy

Authors: J.R. García Cascales, F. Vera García, J.M. Cano Izquierdo, J.P. Delgado

Marín, R. Martínez Sánchez

PII:

$$
\text { S1359-4311(10)00364-9 }
$$

DOI:

10.1016/j.applthermaleng.2010.08.025

Reference: $\quad$ ATE 3218

To appear in: Applied Thermal Engineering

Received Date: 13 September 2009

Revised Date: 22 August 2010

Accepted Date: 24 August 2010

Please cite this article as: JRG. Cascales, FV. García, JMC. Izquierdo, JPD. Marín, RM. Sánchez. Modelling An Absorption System Assisted By Solar Energy, Applied Thermal Engineering (2010), doi: 10.1016/j.applthermaleng.2010.08.025

This is a PDF file of an unedited manuscript that has been accepted for publication. As a service to our customers we are providing this early version of the manuscript. The manuscript will undergo copyediting, typesetting, and review of the resulting proof before it is published in its final form. Please note that during the production process errors may be discovered which could affect the content, and all legal disclaimers that apply to the journal pertain. 
MODELLING AN ABSORPTION SYSTEM ASSISTED BY SOLAR ENERGY

\author{
J.R. García Cascales*, F. Vera García*, J.M. Cano Izquierdo**, J.P. Delgado Marín***, R. \\ Martínez Sánchez*** \\ *Thermal and Fluid Engineering Department, Technical University of Cartagena, 30202 \\ Cartagena, Murcia, Spain \\ **System and Automation Engineering Department, Technical University of Cartagena, 30202 \\ Cartagena, Murcia, Spain \\ ***Energy Management Agency of the Region of Murcia (ARGEM) C/ Pintor Manuel \\ Avellaneda 1, 1ㅇzda., 30001 Murcia, Spain
}

\begin{abstract}
This paper studies the global modelling of an absorption system working with $\mathrm{LiBr}-\mathrm{H}_{2} \mathrm{O}$ assisted by solar energy. It satisfies the air-conditioning necessities of a classroom in an educational centre in Puerto Lumbreras, Murcia, Spain. The absorption system utilises a set of solar collectors to satisfy the thermal necessities of the vapour generator. Several models have been developed for the characterisation of the absorption equipment, one of them based on the manufacturer data catalogue and the others based on neural networks. These are based on the Adaptive Resonance Theory. They are proved to predict the outlet temperature of the absorption system with efficiency. The experimental data obtained during two years of performance have been used for training and validation. For the dynamical simulation of the global system, TRNSYS software is proposed. The model can easily be programmed in Fortran and included in TRNSYS code. The paper is closed drawing some conclusions.
\end{abstract}

KEYWORDS: Absorption system modelling, solar energy, solar refrigeration, neural networks, dynamic simulation

\title{
1. Introduction
}

The main concern of this paper is the study and development of robust models for carrying out the energy analysis of refrigeration equipments assisted by solar thermal energy. The framework in which this development is included, began to be defined in 2005, through a collaboration agreement signed between the Energy Management Agency of the Region of Murcia (ARGEM) and the companies Isofotón S.A. (www.isofoton.com) and Rotartica (www.rotartica.com). The aim of this is to construct and monitor an absorption refrigeration system assisted by solar thermal energy and settle down in the Region of Murcia with the objective of promoting the development and use of such equipments in the Region. The high levels of insolation in the Southeast of Spain during the whole year make the use of thermal energy equipments very attractive, especially for solar assisted air-conditioning systems. As a result of this, a collaboration agreement was signed between ARGEM and the Puerto Lumbreras City Hall. A system with these characteristics which supplies air-conditioning for several classrooms in a local Education Centre was decided to be constructed.

The interest in absorption refrigeration systems has increased in recent decades due to the possibility of using waste heat from gas and steam turbines or renewable energies, solar energy in this case. In addition, they do not contribute to the ozone depletion or to global warming. Aware of the interest in these equipments, a more ambitious plan promoted by ARGEM and the Institute for Diversification and Energy Saving was developed during 2007. Due to this plan, several facilities following the same principles as those in Puerto Lumbreras have been designed and are going to be constructed. One of them is being constructed at the

+ Corresponding author: Tel.: +34 968325 991, fax: + 34968325 999, E-mail address:

jr.garcia@upct.es 
Technical University of Cartagena, Spain which will satisfy the heating and air-conditioning in classroom N.0.1, in block no.2 on the Alfonso XIII Campus. Considering the experience of Puerto Lumbreras and the availability of data, a model was thought to be helpful in the design process of the new facilities. Other experiences with Rotartica systems should also stand out $[1,2]$.

In this paper, several models for single-effect absorption systems which work with a mixture of $\mathrm{LiBr}-\mathrm{H}_{2} \mathrm{O}$ are studied. They use solar energy to separate the refrigerant from the absorbent in the vapour generator and utilise air as heat sink for the condensation. As mentioned above, the system satisfies the cooling necessities of three classrooms in a Puerto Lumbreras education centre. To carry out the modelling, the manufacturer data catalogue and the experimental data measured during the equipment operation in 2006 and 2007 are used. TRNSYS modules, IISIBAT and PREBID will also be used in future works to model the global system and analyse the refrigeration loads of the building. The absorption system model developed can be integrated in a global model and be used during the air-conditioning system design.

Weather data have been provided by the centre of the National Institute of Meteorology in Guadalupe, Murcia. In particular, a data base of radiation, humidity and dry-bulb temperature with series of about 10 years have been used.

The system analysed does not use another energy resource when the absorption equipment cannot provide the necessary energy to the vapour generator. In addition, it has not got a cooling tower which makes it quite appealing from the legionella point of view.

In this work, three different models are provided to analyse the absorption system. One of them is based on the manufacturer data and the others are based on neural networks. The use of neural networks for the characterisation of thermal systems and the estimation of thermal variables is not new $[3,4,5,6]$. The internal behaviour of the absorption system is not known, but despite this, global models are expected to be enough to help the designer throughout the design stage. These models are restricted to systems based on the ROTARTICA system.

A further objective of the work carried out is to analyse several improvements which could be included in the new designs. This will be included in a future work. To do so, the program TRNSYS will be used as was said above. The models presented herein will be used for this study.

The paper has been structured as follows: the facility and the different elements which comprise it are briefly described; special attention is paid to the absorption machine modelling; three different approximations are proposed and will be implemented in TRNSYS in the future; these models with those corresponding to the rest of the devices which compose the facility can be assembled in the IlsiBat environment to study the global system, and finally, several improvements of the system are analysed and some conclusions are drawn.

\section{Nomenclature}

a: $\quad$ FasArt/FasBack input vector

$b$ : $\quad$ FasArt/FasBack output vector

$c_{p}: \quad$ Specific heat at constant pressure $\mathrm{J} /(\mathrm{kg} \cdot \mathrm{K})$.

COP: $\quad$ Coefficient of performance.

F: $\quad$ Unit level
Subscripts:

a: $\quad$ Inertia circuit.

a: $\quad$ ARTMAP module

$b: \quad$ ARTMAP module

$a m b$ : Outdoor conditions.

+ Corresponding author: Tel.: +34 968325 991, fax: + 34968325 999, E-mail address:

jr.garcia@upct.es 


\begin{tabular}{|c|c|c|c|}
\hline$h:$ & $\begin{array}{l}\text { Convective heat transfer coefficient } \\
\mathrm{W} /\left(\mathrm{m}^{2} \cdot \mathrm{K}\right) \text {. }\end{array}$ & $c:$ & $\begin{array}{l}\text { Cold fluid, Cold water } \\
\text { circuit. }\end{array}$ \\
\hline I: & Solar irradiation $\left(\mathrm{W} / \mathrm{m}^{2}\right)$ & frío: & Related to refrigeration. \\
\hline I: & Normalized vector & gen: & Related to vapour \\
\hline$k:$ & Thermal conductivity $\mathrm{W} /(\mathrm{m} \cdot \mathrm{K})$. & & generator. \\
\hline$L:$ & Length $(\mathrm{m})$. & $h:$ & Hot fluid. \\
\hline$m:$ & Mass flow rate $(\mathrm{kg} / \mathrm{s})$. & $i:$ & Input, inlet. \\
\hline$Q:$ & Heat transfer $(\mathrm{kW})$. & $i:$ & Unit number \\
\hline$r:$ & Radius $(\mathrm{m})$ & $k:$ & Unit number \\
\hline$R:$ & Regression coefficient. & $\max :$ & Maximum \\
\hline$T:$ & Temperature $(\stackrel{\circ}{C}, \mathrm{~K})$. & $\min :$ & Minimum \\
\hline$U:$ & Overall heat transfer coefficient $\mathrm{W} /\left(\mathrm{m}^{2} \cdot \mathrm{K}\right)$. & $o:$ & Outlet \\
\hline$x:$ & Unit activation & $w:$ & Water \\
\hline$y:$ & General variable. & & \\
\hline$y:$ & Unit activation & Greek & \\
\hline$W:$ & Unit weight vector & $\rho:$ & Matching parameter \\
\hline & & & $\begin{array}{l}\text { efficiency } \\
\text { diameter }\end{array}$ \\
\hline
\end{tabular}

\section{Global system description}

To model the thermal behaviour of the system, the elements shown in Figure 1 will be taken into account. The objective is to develop a global model which assists the designer in the study of refrigeration systems like this, based on the Rotartica's absorption systems.

Three different circuits may clearly be differentiated: Circuit 1 which connects the solar collectors to the inertia tank; Circuit 2 which connects the tank to the absorption system; and finally, Circuit 3 which is used to send cold water to the fan-coils inside the classrooms.

The weather conditions of the place where the facility is settled are introduced by using the data provided by the centre of the National Institute of Meteorology in Murcia. They will be used to determine the outdoor conditions (solar radiation, long wave radiation, temperature, humidity, sky fictive temperature, and so on).

The solar collectors used in this facility are characterised by an efficiency curve

$$
\varepsilon=0,75-4,5 \frac{T_{i}-T_{a m b}}{l}
$$

For the sake of simplicity and as they are not know, the fan-coils in the systems have been modelled by using a simple model just considering constant efficiency heat exchangers. Thus, if the mass flow rates $\dot{m}_{c} \dot{m}_{h}$, and the input temperatures $T_{c i}$, and $T_{h i}$ are known and the energy balance equations are taken into account

$$
\begin{aligned}
& Q=\dot{m}_{h} c_{p h}\left(T_{h i}-T_{h o}\right) \\
& Q=\dot{m}_{c} c_{p c}\left(T_{c o}-T_{c i}\right) \\
& \mathcal{E}=\frac{Q}{\left(\dot{m} c_{p}\right)_{\min }\left(T_{h i}-T_{c i}\right)} \\
& \text { If } Q_{\max }=\left(\dot{m} c_{p}\right)_{\min }\left(T_{h i}-T_{c i}\right) \text { the outlet conditions can be calculated by } \\
& T_{h o}=T_{h i}-\frac{\varepsilon Q_{\max }}{\dot{m}_{h} c_{p h}} y T_{c o}=T_{c i}+\frac{\varepsilon Q_{\max }}{\dot{m}_{c} c_{p c}} .
\end{aligned}
$$

+ Corresponding author: Tel.: +34 968325 991, fax: + 34968325 999, E-mail address:

jr.garcia@upct.es 
The inertia tank has a volume of $1500 \mathrm{I}$. The tank is isolated and its loss overall heat transfer coefficient is $0.014 \mathrm{~W} /\left(\mathrm{m}^{2} \mathrm{~K}\right)$. The stratification of the tank has been taken into account.

The flow rates in the circuits have been considered constant in the analysis of the global system. A value of $33 \mathrm{l} / \mathrm{min}$ is considered in Circuits 1 and 2 and $40 \mathrm{l} / \mathrm{min}$ in Circuit 3.

As far as the pipe modelling is concerned, the following parameters are known:

- The length and the external diameters of each pipe are, $L_{1}=25 \mathrm{~m}, \emptyset_{1}=22 \mathrm{~mm}$. All of them

are made of copper and are conveniently isolated. $L_{2}=13 \mathrm{~m}, \emptyset_{2}=22 \mathrm{~mm}, L_{3}=25 \mathrm{~m}, \emptyset_{3}=22$

$\mathrm{mm}$

- The overall heat transfer coefficient is calculated by considering the thermal conductivities of the isolation materials are $k_{\text {circuit1 }}=k_{\text {circuit } 2}=k_{\text {circuits }}=k_{\text {armaflex }}=0.045 \mathrm{~W} /(\mathrm{mK})$. The outdoor convective heat transfer coefficient which depends on air velocity is given by $h=8+5 \mathrm{v}$ (assuming an air velocity $v=5 \mathrm{~m} / \mathrm{s}$ a value of $33 \mathrm{~W} /\left(\mathrm{m}^{2} \cdot \mathrm{K}\right.$ ) is obtained).

Finally, taking into account that the pipes are made of copper with a thermal conductivity is $k_{\text {copper }}=386 \mathrm{~W} /(\mathrm{mK})$, the following expression has been used:

$$
\frac{1}{U}=\frac{1}{2 \pi r_{1} L h_{1}}+\frac{\ln \left(r_{2} / r_{1}\right)}{2 \pi L k_{a}}+\frac{\ln \left(r_{3} / r_{2}\right)}{2 \pi L k_{b}}+\frac{1}{2 \pi r_{3} L h_{4}} .
$$

The fluids flowing through each circuit are:

- A mixture of water and glycol in the case of Circuits 1 and 2 which has a specific heat at constant pressure $c_{p}=3,8 \mathrm{~kJ} /(\mathrm{kg} \cdot \mathrm{K})$.

- Water, in the case of Circuit 3 with $c_{p}=4,186 \mathrm{~kJ} /(\mathrm{kg} \cdot \mathrm{K})$.

\section{Absorption system modelling}

There are two possibilities for the study on thermal systems. The most common is based on the $1^{\text {st }}$ law of Thermodynamics $[7,8]$, which only refers to the conservation of energy and does not offer any information on how, where, and how much the system performance is degraded. The alternative is the study of the performance and the entropy generation or the exergy of the system on the basis of the $2^{\text {nd }}$ law of Thermodynamics [9].

In this work, three different approximation levels of the absorption system are presented. The first one is based on the manufacturer data and lays in the first category [10]. The manufacturer information available regarding the behaviour of the absorption system includes its refrigeration heat and coefficient of performance (Figure 2 and 3 ). These are functions of the cooling water temperature going out from the absorption machine to the fan-coils. All these data correspond to a working temperature of $90 \stackrel{\circ}{ } \mathrm{C}$ at the inlet of the vapour generator.

The two other approximations are based on neural networks, and in a certain manner lay in the first type of analyses. For their development, experimental data are needed. As was mentioned, this facility has been working since 2006 (in cooling mode during the summers) and the data acquisition system has been registering the following data every five minutes:

+ Corresponding author: Tel.: +34 968325 991, fax: + 34968325 999, E-mail address:

jr.garcia@upct.es 
- Mass flow rate in every circuit.

- Input and outlet temperatures at the absorption system in Circuits 2 and 3.

- Outdoor temperature.

\subsection{One-curve model}

In this approximation, the behaviour of the absorption system is characterised by means of one of the curves in Figures 2 and 3. The curve corresponding to the inlet temperature of water at the condensation circuit $T_{\mathrm{wi}}=40^{\circ} \mathrm{C}$. The equations of these curves have been obtained by a minimum square fit.

$$
\begin{aligned}
& Q_{\text {frio }}=0.0055 T_{\text {co }}^{2}+0.1981 T_{\text {co }}-0.7626(\mathrm{~kW}) \text { with } R^{2}=0.9991 \text {. } \\
& \operatorname{COP}=0.0016 T_{c o}^{2}+0.0738 T_{c o}-0.1779 \text { with } R^{2}=0.9986 \text {. }
\end{aligned}
$$

Taking into account these Equations, the model proposed can be extrapolated to different conditions. If curves for other temperatures were available, the model would improve considerably. Otherwise, the absorption system model follows the algorithm described in the flux diagram of Figure 4, where:

$Q$ : refrigeration heat $(\mathrm{kW})$.

$\dot{m}$ : mass flow rate $(\mathrm{kg} / \mathrm{s})$.

$c_{p}$ : specific heat at constant pressure $(\mathrm{J} /(\mathrm{kg} \cdot \mathrm{K}))$.

$T$ : temperature $(\stackrel{\circ}{-C})$.

subscripts:

ci: cold fluid input.

co: cold fluid output.

wi: condensation water inlet.

wo: condensation water outlet.

Following the COP is calculated the rest of the variables are calculated, so if

and

$$
\text { COP }=\frac{Q_{\text {frio }}}{\text { Supplied energy }}
$$

$$
\text { Supplied energy }=W_{\text {pump }}+Q_{\text {gen }}
$$

the heat exchanged in the vapour generator $Q_{g e n}$ is

$$
Q_{\text {gen }}=\frac{Q_{\text {frio }}}{\operatorname{COP}}-W_{\text {pump }}
$$

where $W_{\text {pump }}$ is the work at the pump.

Taking into account that $T_{a i}$ is known, the temperature of the water going from the absorption system to the inertia tank $T_{a o}$ can be obtained from

so that

$$
\begin{aligned}
& Q_{g e n}=\dot{m}_{a}\left(\mathrm{~h}_{a i}-\mathrm{h}_{a o}\right) \\
& Q_{g e n}=\dot{m}_{a} \mathrm{c}_{\mathrm{p}}\left(T_{a i}-T_{a o}\right)
\end{aligned}
$$

$$
T_{a o}=T_{a i}-\frac{Q_{g e n}}{\dot{m}_{a} c_{p}} .
$$

In order to test the accuracy of this model, the results measured in June, July and September, 2007 were contrasted with those provided by the model. They were obtained by giving the following inputs to the model: the inlet temperatures and the mass flow rates of water in the

+ Corresponding author: Tel.: +34 968325 991, fax: + 34968325 999, E-mail address:

jr.garcia@upct.es 
cold water and hot water circuits. The results obtained (Figure 5 and 6 ) are acceptable enough for a first characterisation of the absorption system. It should not be forgotten that this curve is for a constant temperature of the water coming from the inertia tank at $90{ }^{\circ} \mathrm{C}$ and a constant inlet temperature of the water used to cool the condenser equal to $40^{\circ} \mathrm{C}$. The reader should be aware that this is a first approximation.

Taking into account the previous results, it is noticed that the tendency and the mean value of this comparison are quite close, so the quality of the model may be enough for the type of study considered in this work. Otherwise, in the following section, two other approaches are presented.

\subsection{Neural network modelling}

Artificial neural networks are an alternative when talking about tackling problems related to the identification and control of dynamic systems [11]. Among the great amount of proposed neural network models, neuro-fuzzy systems are an attempt to integrate fuzzy logic principles and the fuzzy sets in neural-like schemes. Among the proposed models, the FasArt and FasBack models have been chosen. They are based on the Adaptive Resonance Theory (ART) and introduce an interpretation of neural models such as the Fuzzy Logic Systems (FLS). The FasArt and FasBack models have been used in process identification and control problems where they have proven to have a high efficiency $[12,13]$.

The FasArt architecture corresponds to that of the Fuzzy ARTMAP model [14], which is graphically described in Figure 7. It is composed by two Fuzzy ART categorisation modules related to each other by means of an associative memory (Inter-ART Map). In the learning phase, the input vector $\mathbf{a}$ and its associated output $\mathbf{b}$ are given to the network. In the test phase, the network will provide the predicted output.

The algorithm describes the FasArt performance and is based on establishing a relationship between the activation function of the level F2 units and the Fuzzy-ART modules. It also shows a belonging function to a fuzzy-set which is defined as a fuzzy-class associated to this unit. The form of this activation-belonging function is determined by the weights associated to each unit according to Figure 8 . The learning in the ART modules modifies the weights associated to the activated unit according to the value of the input which has activated it (learning by matching). In the case of the unit weight of the Inter-ART, the learning is carried out by basing on the maximum generalisation principle with minimum prediction error, which is implemented by means of the reset Inter-ART mechanism. This allows the relationships (IF-THEN rules) between classes (fuzzy sets) generated in the ART-a module (premise) and those generated in the ART-b (consequence) to be defined.

If the performance of FasArt includes the learning by matching, the FasBack model also introduces the learning based on the minimisation optimisation by means of the prediction error minimisation. The particular characteristics of FasArt permit this optimisation to be carried out in a local form, by involving only those units associated to fuzzy-rules which are activated when the input to learn is introduced. This mechanism keeps incremental learning characteristics and avoids catastrophic forgetting problems associated to neural models based on mathematical error minimization. This learning process is not modified by the basic structure of the FasArt model, and therefore, the dual interpretation is kept as ART-like neural network and fuzzy logic system (FLS).

+ Corresponding author: Tel.: +34 968325 991, fax: + 34968325 999, E-mail address:

jr.garcia@upct.es 
The results presented in the literature ensure that it is possible to represent an arbitrary function by means of a fuzzy-logic system with an arbitrary degree of accuracy [15]. This allows the possibilities of applying the FasArt y FasBack models to be guessed. As was mentioned above, they implement the FLS to system identification problems by taking advantage of their learning capabilities and by means of their numerical examples.

For the training stage, the FasArt and FasBack models have been fed with data corresponding to the months: June, July and August, 2006 and June, July and September, 2007. The instrumentation equipment reads a measure every 5 minutes. For the validation stage, the data corresponding to September 2006 have been used.

The neural network must be fed with registered data of the absorption equipment. In the training stage the data considered to have certain influence in the behaviour of the machine are:

- Inlet temperature, $T_{c i}$ and mass flow rate of the air-conditioning circuit $\dot{m}_{c}$ (evaporator).

- Inlet temperature $T_{a i}$ and mass flow rate of the tank circuit $\dot{m}_{a}$ (vapour generator).

- Ambient temperature $T_{a m b}$.

Thus, the learning vector introduced in the ART-a module of the architecture is defined by $\mathbf{a}=\mathbf{1}$ $\left.T_{c i}, \dot{m}_{c} T_{a i} \dot{m}_{a} T_{a m b}\right)$.

For the supervision in the learning phase, the output values of the temperatures $T_{c o}$ and $T_{a o}$ and the COP must be provided. These are the values to introduce in the ART-b module of the architecture.

At this stage of the test, the network will provide the prediction for $\left(T_{c o} T_{a o} \mathrm{COP}\right)$. The results obtained in the validation phase with the FasArt model for the characteristic variables, output temperatures to the fan-coils and to the inertia tank, are gathered in Figure 9 and 10, respectively. The results obtained with the FasBack model are shown in Figures 11 and 12 . The FasBack learning makes it give better results as it is appreciated in the results obtained. In Figure 13, the results obtained for the COP with the FasBack network have been included. Unlike the temperatures results, COP presents some scattering. This is due to the great amount of wrong experimental data used in the learning phase for the COP. This difficulty is attributed to the high inaccuracy of the electric transducers used in the experiments. Otherwise, the ability of the model to predict properly anomalous experimental results is also observed in this case; COPs evaluated with measured values such us those with abcisa equal to $1.15,1.32$, and 1.59 are predicted with a lower value $0.76,0.79$, and 0,76 respectively which is correct. It is also remarkable that other anomalous states such as those with COPs different from zero when the system is stopped are put to zero by the model.

\section{Conclusions}

Several levels of approximation have been introduced to model an absorption system assisted with solar thermal energy. One of them is based on manufacturer data: Cooling capacity and COP of the equipment as a function of the cool water temperature. Despite being a rough estimate, the results it provides are good enough as a first approximation. The other two models are based on neural networks: FasArt and FasBack. They are based on the Adaptive Resonance Theory, combining neural networks and fuzzy logic systems. The results obtained

+ Corresponding author: Tel.: +34 968325 991, fax: + 34968325 999, E-mail address:

jr.garcia@upct.es 
show that the network predicts with a fair efficiency the value of $T_{c o}$ and $T_{a o}$. The prediction of the COP is not so accurate since the number of anomalous experimental results used in the learning phase is high. To do this properly, electric energy transducers should be replaced and variables such as the energy supplied to the system should be provided to the model during the learning stage (only $T_{c i}, \dot{m}_{c} T_{a i} \dot{m}_{a} T_{a m b}$ have been provided in our study). Otherwise, it has been proved that the use of neuro-fuzzy models permits an interpretation of the system performance by using IF-THEN rules which describe correlations between the variables of the system.

As mentioned in this paper, these models will be included in TRNSYS in order to model the global system and will be used for the study of different configurations of absorption airconditioning systems assisted with solar energy.

\section{Acknowledgements}

This research has been financed by Energy Management Agency of the Region of Murcia, Spain (ARGEM) under contract 2003/07ITF.

\section{References}

[1] M. Izquierdo, R. Lizarte, J.D. Marcos, G. Gutiérrez, Air conditioning using an air-cooled single effect lithium bromide absorption chiller: Results of a trial conducted in Madrid in August 2005, Applied Thermal Engineering, 28, Issues 8-9, June (2008), 1074-1081.

[2] M.C. Rodríguez Hidalgo, P. Rodríguez Aumente, M. Izquierdo Millán, A. Lecuona Neumann, R. Salgado Mangual, Energy and carbon emission savings in Spanish housing air-conditioning using solar driven absorption system, Applied Thermal Engineering, 28, Issues 14-15, (2008), 1734-1744.

[3] A. Sözen, M. Kurt, M.A. Akçayol, M. Özalp, Performance prediction of a solar driven ejectorabsortion cycle using fuzzy logic, Renewable Energy, 29 (4) (2004) 53-71.

[4] A. Sözen, M. A. Akçayol, Modelling (using artificial neural-networks) the performance parameters of a solar-driven ejector-absorption cycle, Applied Energy, 79 (3) (2004) 309-325.

[5] G. Mihalakakaou, On estimating soil surface temperature profiles, Energy and Buildings, 34 (3) (2002) 251-259.

[6] S. Alam, S.C. Kaushik, S.N. Garg, Assessment of diffuse solar energy under general sky condition using artificial neural network, Applied Energy, 86 (4) (2009) 554-564.

[7] R. J. Romero, W. Rivera, R. Best, Comparison of the theoretical performance of a solar air conditioning system operating with water/lithium bromide and an aqueous ternary hydroxide. Solar Energy Materials and Solar Cells, 63 (4) (2000) 387-399.

[8] D.W. Sun, Computer simulation and optimization of ammonia-water absorption refrigeration systems. Energy Sources, 19 (7) (1997) 677-690.

[9] O. Kaynalkli, R. Yamnkaradeniz, Thermodynamic analysis of absorption refrigeration system based on entropy generation, Current Science, 92 (4) (2007) 472-479.

+ Corresponding author: Tel.: +34 968325 991, fax: + 34968325 999, E-mail address:

jr.garcia@upct.es 
[10] J.R. García Cascales, F. Vera García, J.M. Cano-Izquierdo, J.P. Delgado-Marín, R. MartínezSánchez, Aspectos sobre el modelado y el diseño de un sistema de refrigeración por absorción asistido con energía solar in Proceedings of the XIV Congreso Ibérico y IX Iberoamericano de Energía Solar, Vigo, Galicia, Spain, 17-21 June (2008).

[11] K. Narendra, K. Parthasarathy, Identification and control of dynamical systems using neural networks, IEEE Transactions in Neural Networks, 1 (1) (1990) 4-27.

[12] J.M. Cano-Izquierdo, E. Gómez-Sánchez, Y. Dimitriadis, J. López, Learning from noisy information in FasArt and FasBack neuro-fuzzy systems", Neural Networks, 7 (3) (2001) 407425.

[13] M. Araúzo, J.M. Cano-Izquierdo, E. Gómez-Sánchez, M. López, Y. Dimitriadis, J. López, Automation of a penicillin production process with soft sensors and a adaptive controller based on neuro fuzzy systems, Control Engineering Practice, 12 (2004) 1073-1090.

[14] G. Carpenter, S. Grossberg, N. Markuzon , J. Reynolds, Fuzzy ARTMAP: A neural network architecture for incremental supervised learning of analogue multidimensional maps, IEEE Transactions on Neural Networks, 3 (1992) 698-713.

[15] J. Castro, M. Delgado, Fuzzy systems with defuzzification are universal approximators. IEEE Transaction on Systems, Man, and Cybernetics-Part B: Cybernetics, 26 (1) (1996) 149-152. 


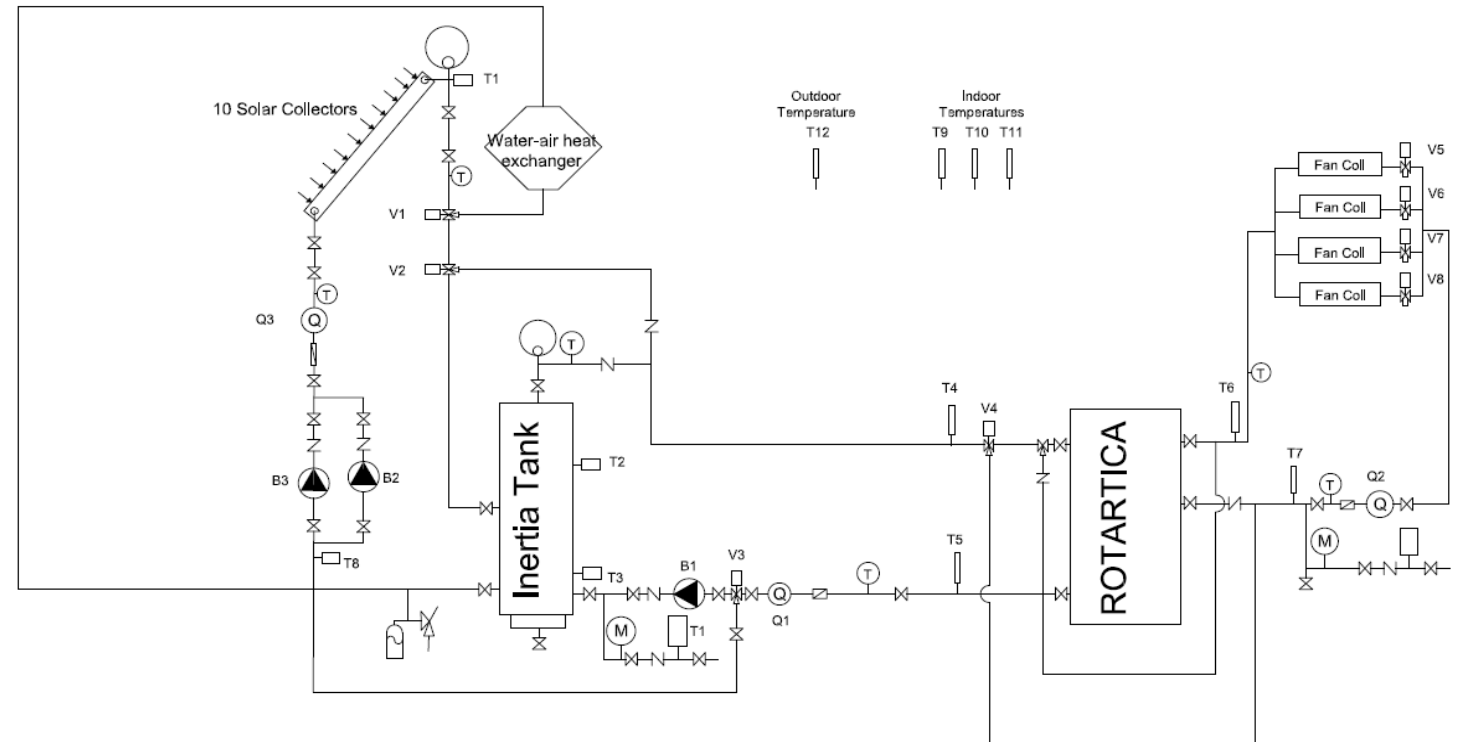

Figure 1 . Schematic picture of the facility studied in this paper.

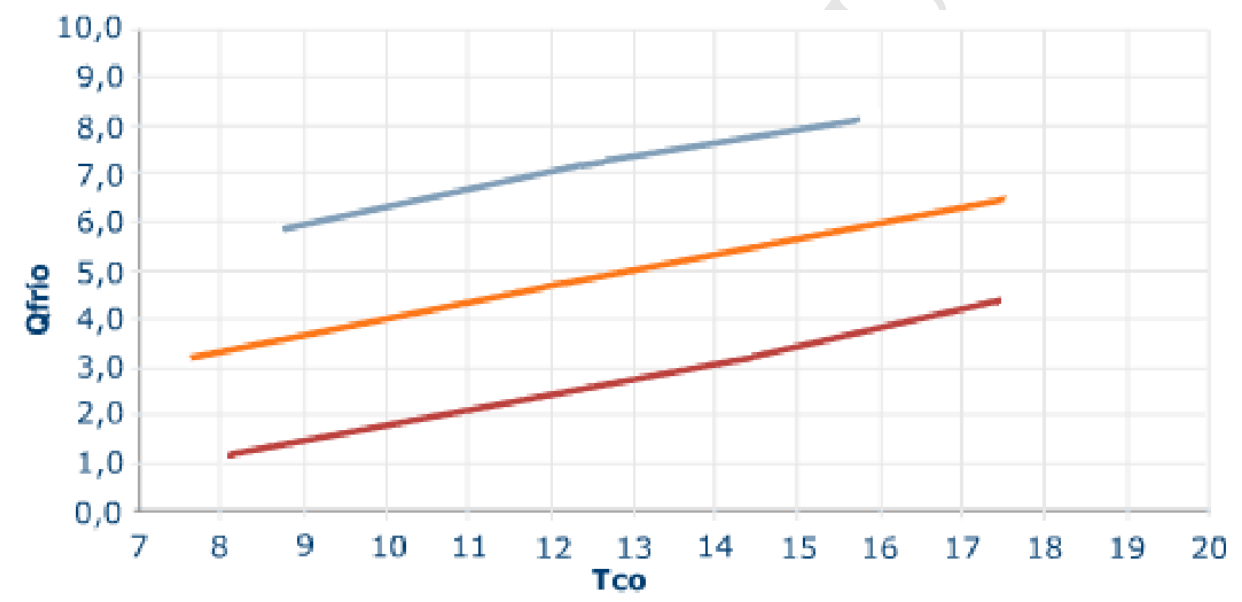

$\Delta T w i=35 \Delta T w i=30 \wedge T w i=40$

Figure 2. Refrigeration heat of the absorption system ( $\mathrm{Q}_{\text {frio }}$ is in $\mathrm{kW}$, manufacturer catalogue).

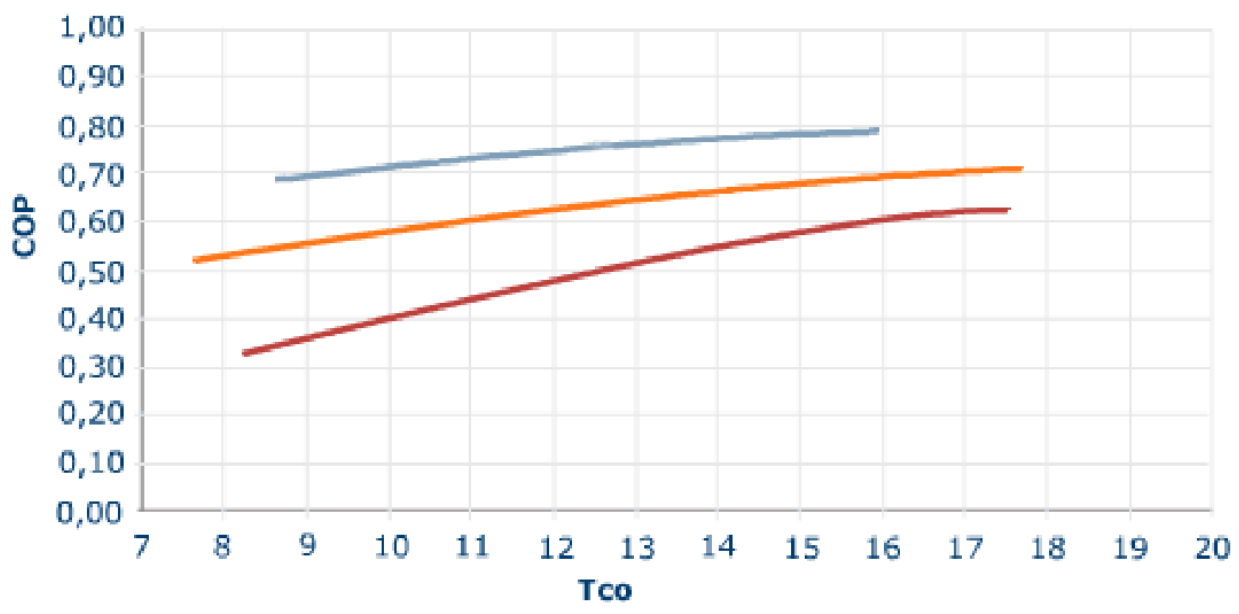

$\Delta$ Twi=35 $\Delta$ Twi=30 $\Delta$ Twi $=40$

Figure 3. COP of the absorption system (manufacturer catalogue).

+ Corresponding author: Tel.: +34 968325 991, fax: + 34968325 999, E-mail address:

jr.garcia@upct.es 


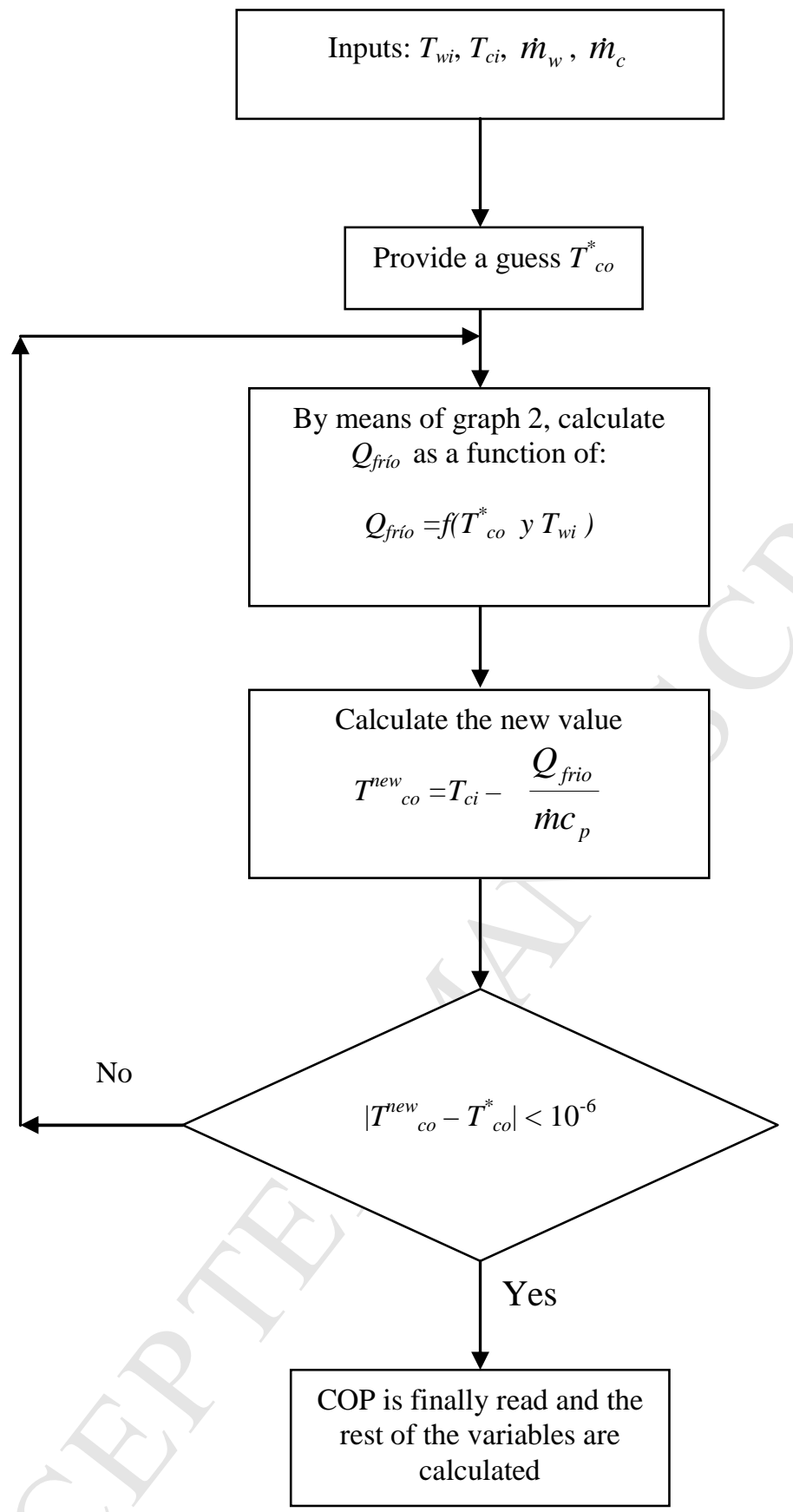

Figure 4. Flux diagram: calculation of the output variables of the absorption system. 


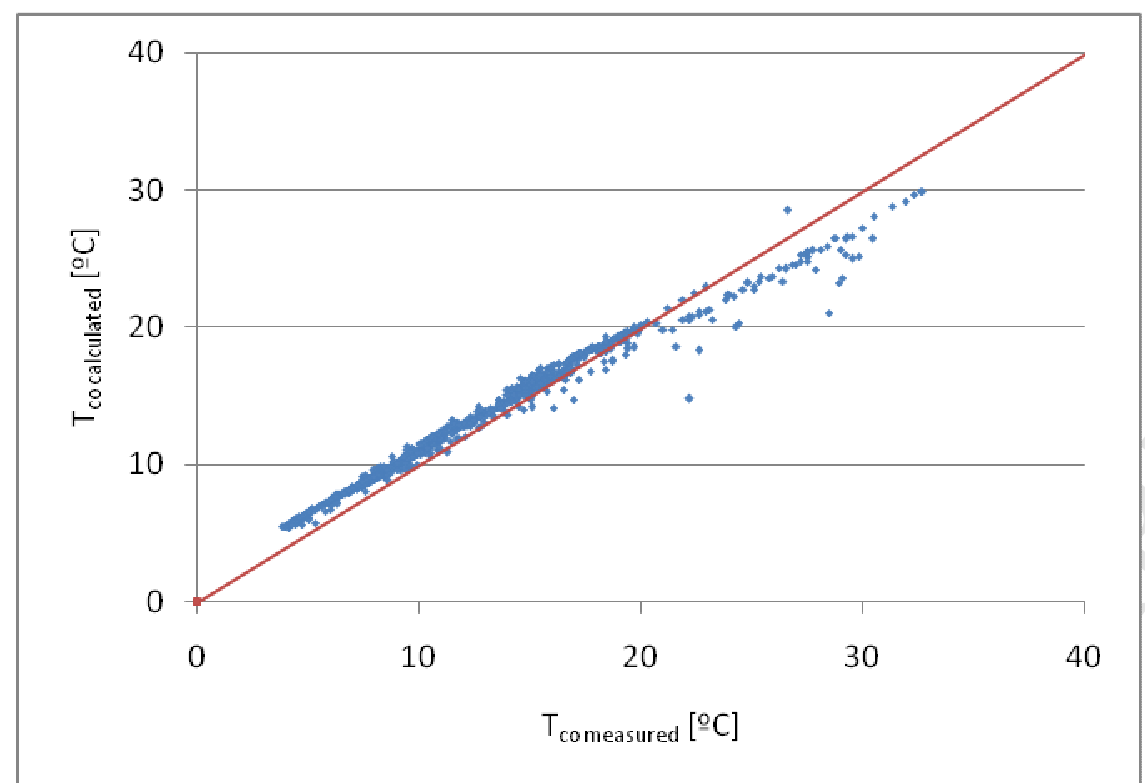

Figure 5. Comparison between the calculated and the measured values of $T_{c o}$.

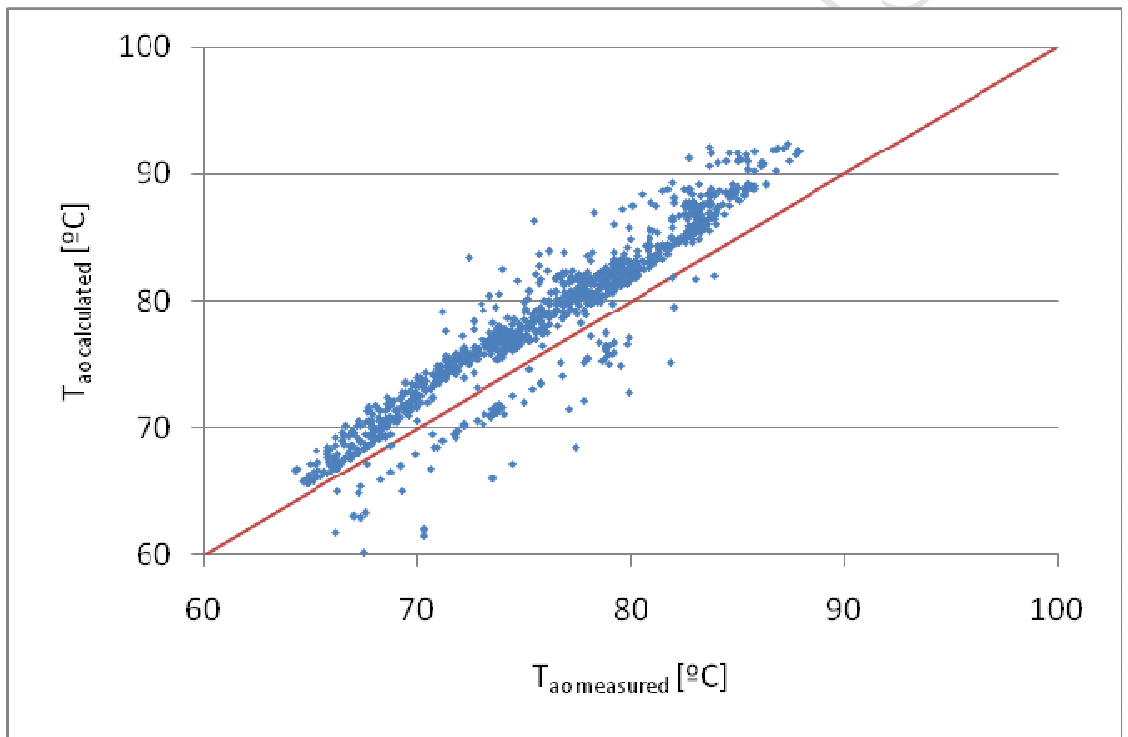

Figure 6. Comparison between the calculated and the measured values of $T_{a 0}$.

+ Corresponding author: Tel.: +34 968325 991, fax: + 34968325 999, E-mail address: jr.garcia@upct.es 


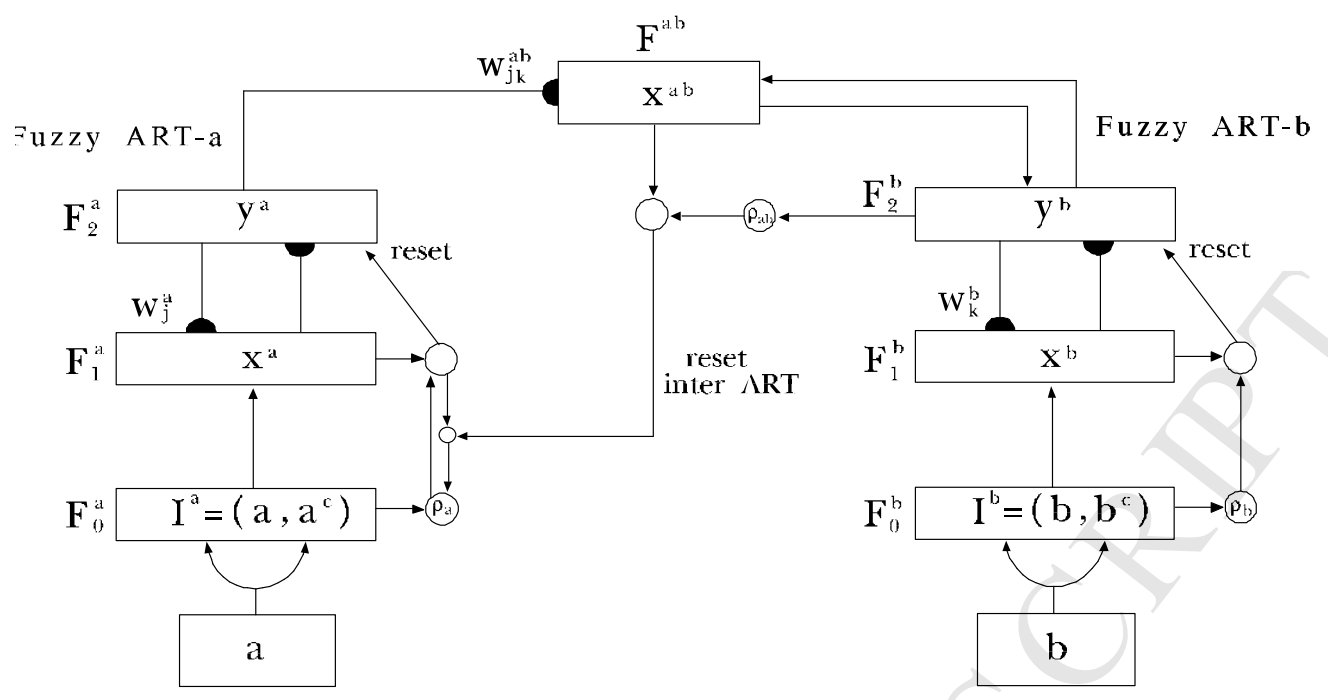

Figure 7. Fuzzy ARTMAP architecture.

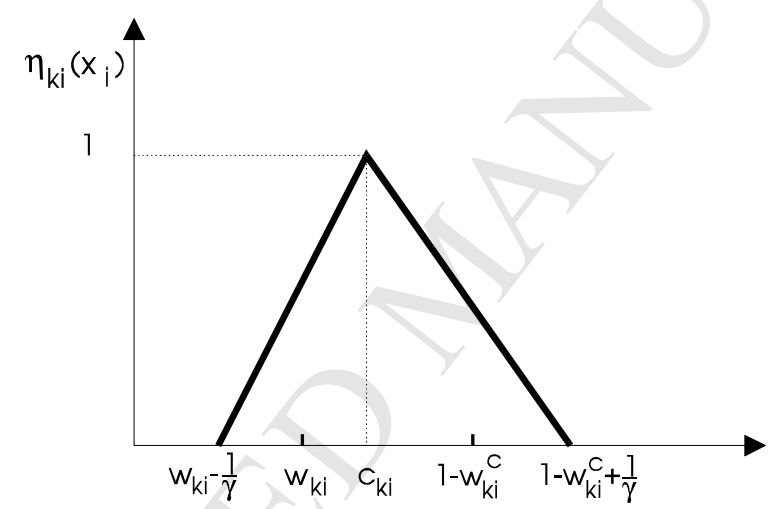

Figure 8. FasArt activation function. 


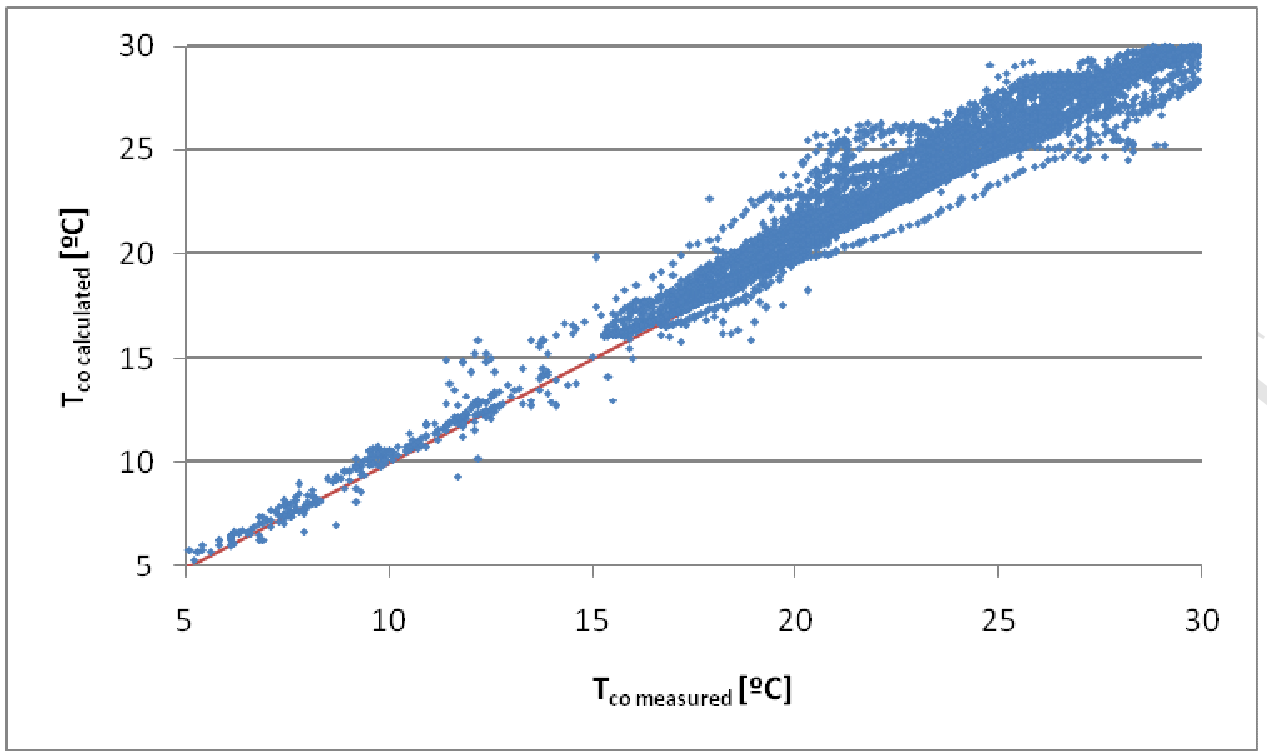

Figure 9. Comparison between measured and calculated results using FasArt $T_{c o}(\stackrel{\circ}{ } \mathrm{C})$.

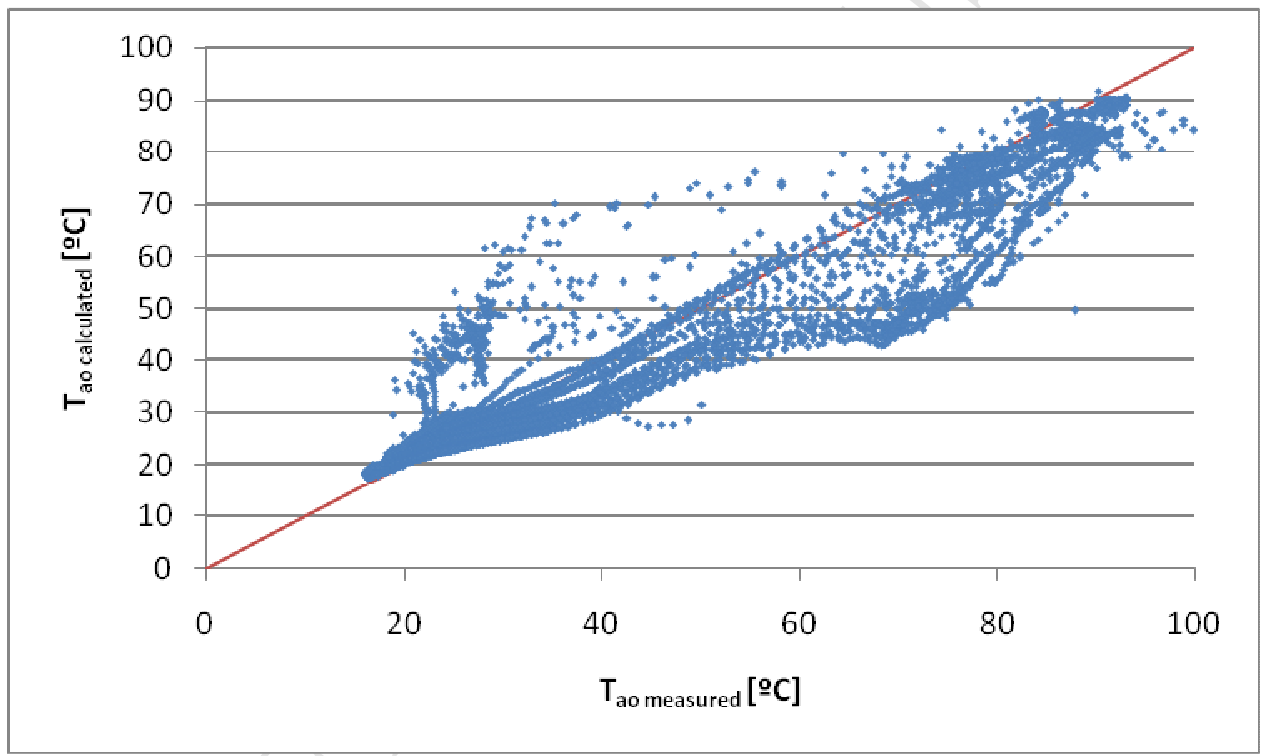

Figure 10. Comparison between measured and calculated results using FasArt $T_{a o}(\stackrel{\circ}{ } \mathrm{C})$. 


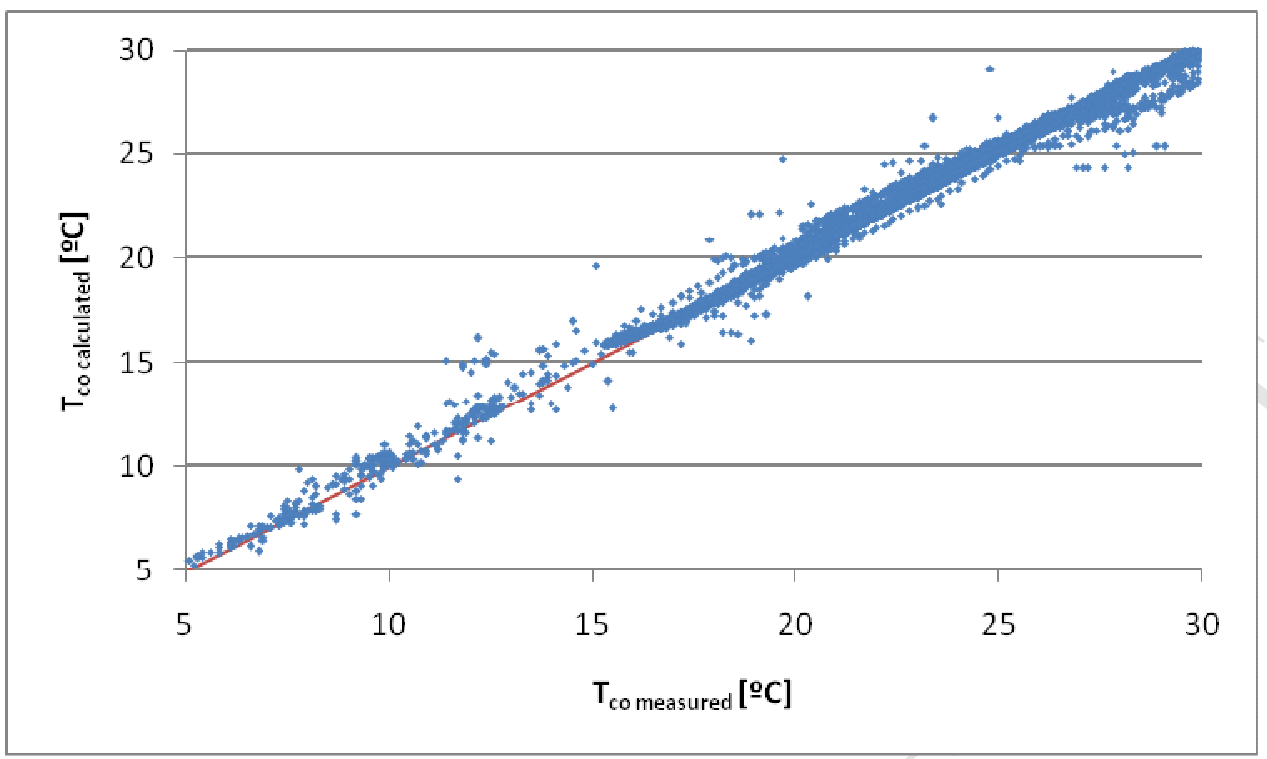

Figure 11. Comparison between measured and calculated results using FasBack $T_{c o}$ (으).

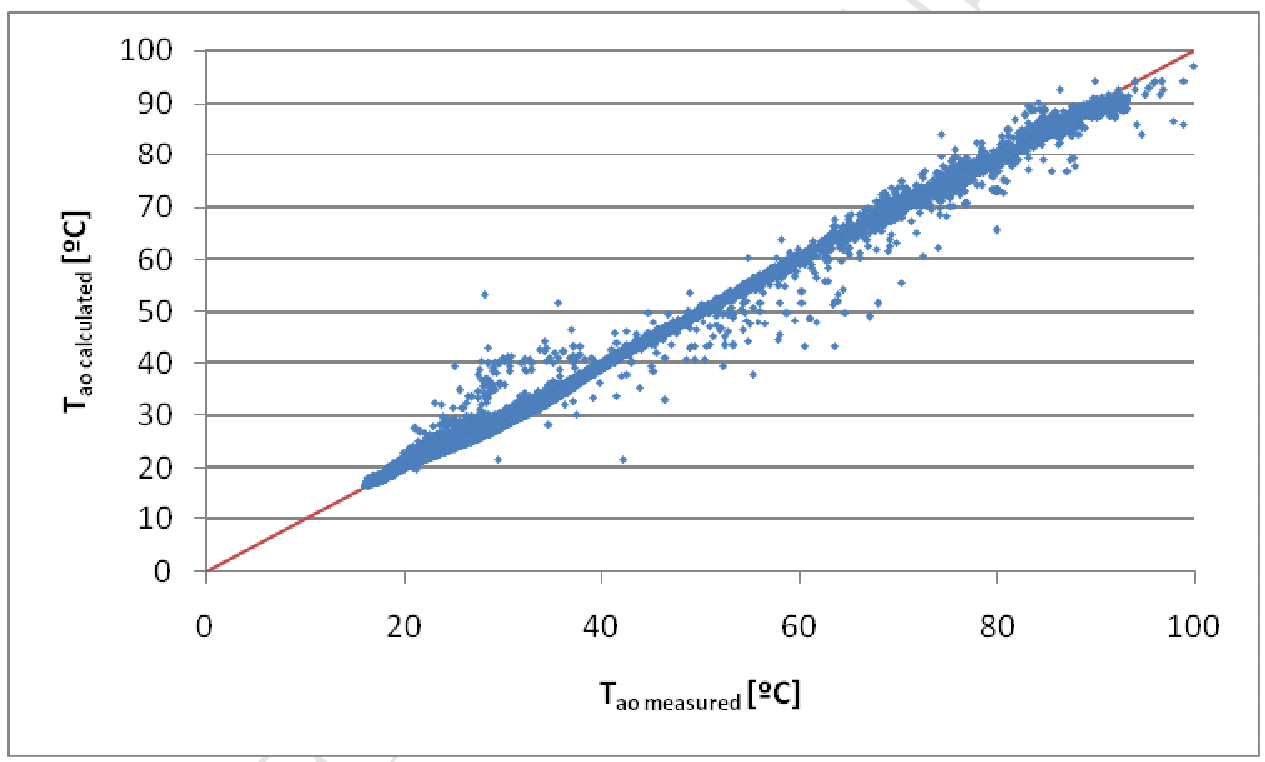

Figure 12. Comparison between measured and calculated results using FasBack $T_{a o}(\stackrel{\circ}{ } \mathrm{C})$. 


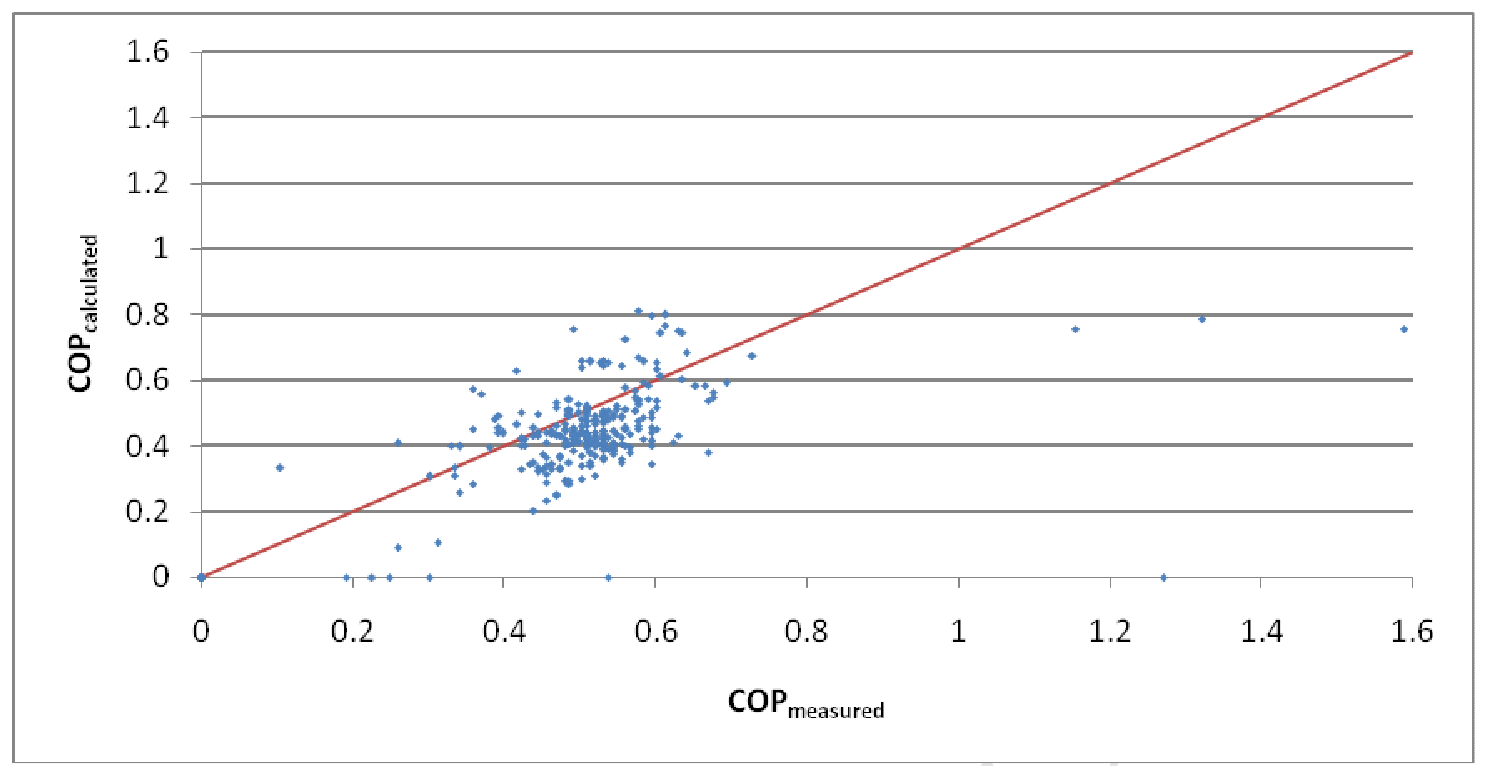

Figure 13. Comparison between measured and calculated results using FasBack COP.

+ Corresponding author: Tel.: +34 968325 991, fax: + 34968325 999, E-mail address: jr.garcia@upct.es 


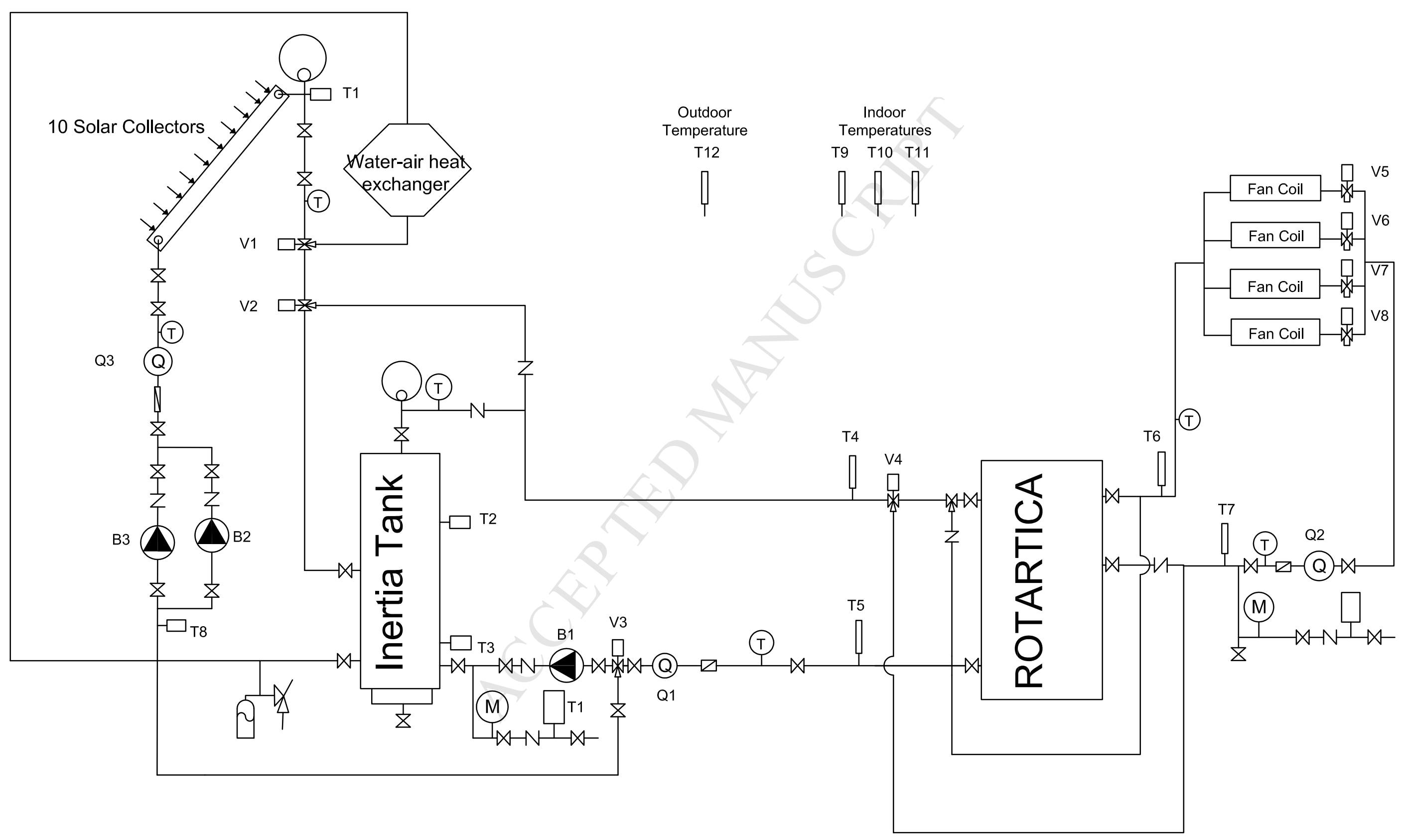




\section{ACCEPTED MANUSCRIPT}

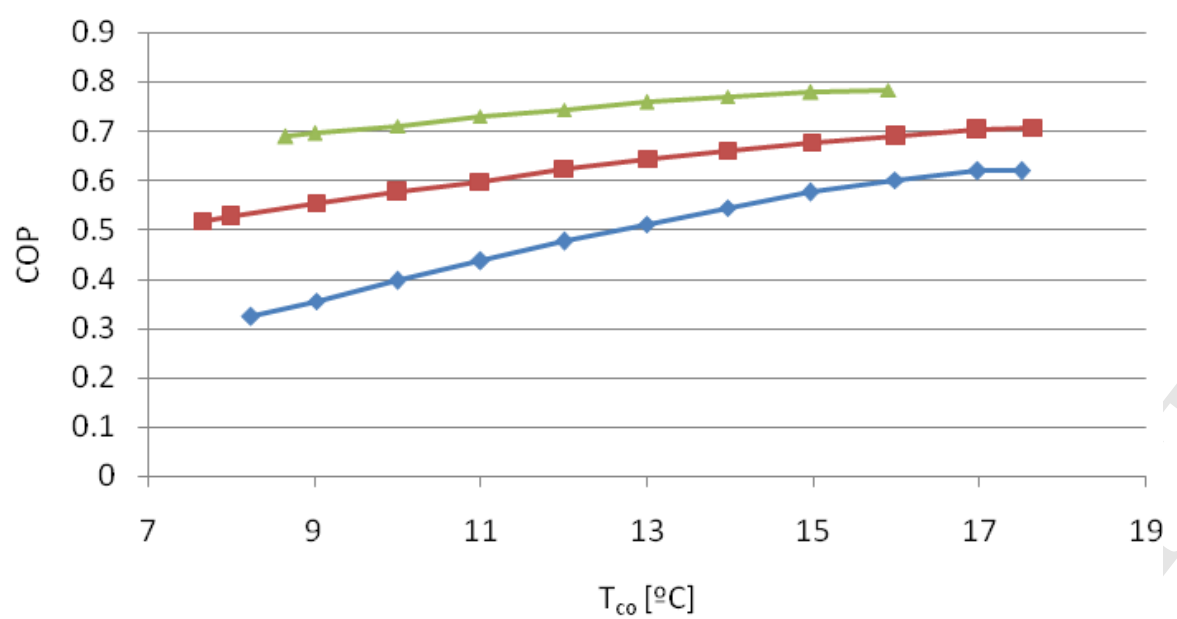

$\multimap$ Twi $=40^{\circ} \mathrm{C} \longrightarrow$ Twi $=35^{\circ} \mathrm{C} \longrightarrow$ Twi $=30^{\circ} \mathrm{C}$

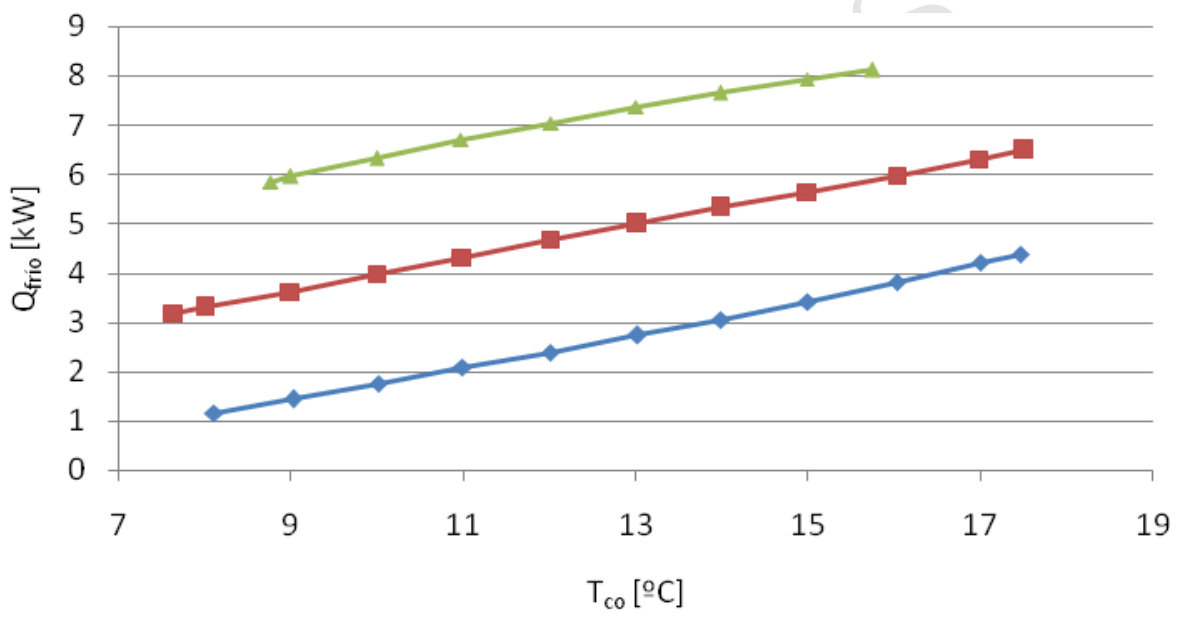

$\multimap$ Twi $=40^{\circ} \mathrm{C} \longrightarrow$ Twi $=35^{\circ} \mathrm{C} \longrightarrow$ Twi $=30^{\circ} \mathrm{C}$ 